\title{
Breast cancer risk in a screening cohort of Corsunat Asian and white British/Irish women from Manchester UK
}

\author{
D. Gareth Evans ${ }^{1,3,7^{*}}$, Adam R. Brentnall ${ }^{4}$, Michelle Harvie ${ }^{3}$, Susan Astley ${ }^{2,3}$, Elaine F. Harkness ${ }^{2,3}$, Paula Stavrinos ${ }^{3}$, \\ Louise S. Donnelly ${ }^{3}$, Sarah Sampson ${ }^{3}$, Faiza Idries ${ }^{3}$, Donna Watterson ${ }^{3}$, Jack Cuzick ${ }^{4}$, Mary Wilson ${ }^{3}$, Anil Jain $^{3,5}$, \\ Fiona Harrison ${ }^{3}$, Anthony J. Maxwell ${ }^{2,3}$ and Anthony Howell ${ }^{2,3,6}$
}

\begin{abstract}
Background: The differences between breast cancer risk factors in white British//rish and Asian women attending screening in the UK are not well documented.

Methods: Between 2009-15 ethnicity and traditional breast cancer risk factors were self-identified by a screening cohort from Greater Manchester, with follow up to 2016. Risk factors and incidence rates were compared using agestandardised statistics (European standard population).

Results: Eight hundred and seventy-nine Asian women and 51,779 unaffected white British/lrish women aged 46-73 years were recruited. Asian women were at lower predicted breast cancer risk from hormonal and reproductive risk factors than white British/Irish women (mean 10 year risk $2.6 \%$ vs $3.1 \%$, difference $0.4 \%, 95 \% \mathrm{Cl} 0.3-0.5 \%$ ). White British/Irish women were more likely to have had a younger age at menarche, be overweight or obese, taller, used hormone replacement therapy and not to have had children.. However, despite being less overweight Asian women had gained more weight from age 20 years and were less likely to undertake moderate physical activity. Asian women also had a slightly higher mammographic density. Asian age-standardised incidence was 3.2 (95\%Cl 1.6-5.2, 18 cancers) per thousand women/year vs 4.5 (95\% Cl 4.2-4.8, 1076 cancers) for white British/Irish women.
\end{abstract}

Conclusions: Asian women attending screening in Greater Manchester are likely to have a lower risk of breast cancer than white British/Irish women, but they undertake less physical activity and have more adult weight gain.

Keywords: Breast cancer, Risk factors, Ethnicity, United Kingdom

\section{Background}

The risk of breast cancer, attendant risk factors and the uptake and performance of breast screening are not well understood in ethnic minority groups in the United Kingdom (UK), including those with an Asian ancestry. Screening uptake is likely to be substantially lower in Asian women, and particularly in women of Pakistani or Bangladeshi origin in the UK [1-3]. However, much of the evidence to date has been based on linkage from

\footnotetext{
* Correspondence: Gareth.Evans@cmft.nhs.uk

'Department of Genomic Medicine, Division of Evolution and Genomic

Science, MAHSC, University of Manchester, Central Manchester NHS

Foundation Trust, Oxford Road, Manchester, UK

${ }^{3}$ Nightingale \& Prevention Breast Cancer Centre, University Hospital of South

Manchester, Manchester, UK

Full list of author information is available at the end of the article
}

census data because the National Health Service Breast Screening Programme (NHSBSP) does not collect ethnicity data, nor is it known when Asian women are invited for screening. Breast cancer rates are lower for Asian women in their native countries [4], but appear to become intermediate when Asian women move to higher incidence countries [5]. It is thought that this reflects westernisation of risk factors such as delayed or reduced parity [6]; however, the exact reasons for this remain unclear [4].

The only previous study to have accessed breast cancer risk factors and observed risk in Asian women resident in the UK was in the Million Women Study cohort [16]. This found that recorded risk factors for age at menarche, hormone therapy, alcohol and breast cancer family 
history, were more protective amongst Asian women compared with white women, whilst Body Mass Index (BMI) was comparable. Additional adjustment for these risk factors for the disease showed that breast cancer incidence was similar to that of white women; these risk factors accounted for almost all the differences in risk.

The NHSBSP operates a three-yearly screening cycle, inviting all women aged 50-70y, and some women aged 47-49 or 70-73y through an on-going cluster randomized trial. During the 2011-12 screening round of the NHSBSP, overall coverage was 77\% [7]. Uptake of routine invitations for women aged 50-70 years was 73\% with comparatively lower uptake (68\%) in the $71-74$ year age group. A total of 15,749 women aged 45 and over had cancers detected by the screening programme in 2011-12, a rate of 8.1 cases per thousand women screened, with the cancer detection rate being highest amongst women over 70 years (13.9 per thousand women screened).

The Greater Manchester Breast Screening Programme (GMBSP) invites women aged 47-73 years in five main areas of Greater Manchester: Tameside, Oldham, Salford, Manchester and Trafford. Within each of these areas there are several local screening sites. Ethnic minorities make up just over $20 \%$ of the population of these five areas, about half of which are of Asian ethnicity [8]. Uptake to breast screening in Greater Manchester is typically slightly lower than the national average, being 70\% versus 73\% of eligible women screened during 2011-12.

The aim of this study was to determine whether there were differences in breast cancer risk factors between screening attendees who identified themselves as "Asian or Asian British" compared with "white British or Irish", and how this might influence breast cancer rates between the two populations.

\section{Methods \\ Cohort}

Recruitment to the Predicting Risk of Cancer at Screening (PROCAS) study was carried out in two phases [9]. In phase one (October 2009-October 2012) all women invited for breast screening in the GMBSP were sent an invitation to participate in the study. As screening is triennial, this meant that all women attending screening during the recruitment period were invited once during this time. In phase two (November 2012-March 2015) women not previously screened were invited; thus women recruited during this phase were substantially younger than women recruited in phase one.

The study was approved by North West 7 Research Ethics Committee - GM Central (reference 09/ H1008/81).

\section{Risk factors}

A two-page questionnaire was devised to collect selfreported ethnicity (with categories for Asian or Asian British, black or black British, mixed, white British or Irish, other [with free text]; Jewish Origin or Jewish Ashkenazi) and known breast cancer risk factors which are included in the Tyrer-Cuzick model $[9,10]$. This included family history information (number and ages of sisters; current age or age at death of mother; and details of any relatives affected by breast or ovarian cancer), hormonal risk factors (age of menarche and first pregnancy, parity, menopausal status and hormone therapy use) and current weight and height. We also collected information on some additional breast cancer risk factors: weight at age 20 years, from which we determined percentage of adult weight gain (current weight/weight at 20 years) $\times 100 \%$, alcohol consumption and amount of moderate physical activity in the past week [11].

Women were mailed the questionnaire and a consent form in the interval between their screening invitation and attendance for mammography. Consent for entry to the study was taken at the time of the screening appointment. Questionnaire data was entered onto a study database and using the Tyrer-Cuzick version 6 risk calculator, a 10 year risk score for each individual was automatically produced [10].

Mammographic density was measured at entry by visual assessment for the first 53,000 women enrolled. Two expert readers from a pool of 18 assessed percentage density on each mammographic examination (usually four views: left and right medio-lateral oblique and cranio-caudal) using a 0 to $100 \%$ visual analogue scale (VAS), as previously described [12]. The average of all VAS scores for each woman was used in the analysis.

\section{Breast cancer incidence and vital statuses}

Breast cancer diagnoses, tumour characteristics and vital statuses were obtained from the screening programme and a local cancer intelligence service using National Health Service (NHS) numbers. Follow up was censored at either breast cancer diagnosis, death or on 31/12/2016 depending on which occurred earliest. Incidence used invasive cancer and ductal carcinoma in situ diagnoses, which was the pre-defined study endpoint and was done in other analyses of risk factors from this cohort, also partly due to the similarity of risk factors for both types of disease [12].

\section{Statistical methods}

We estimated the percentage uptake to the study amongst Asian women as the relative proportion of Asian women in 5 year age bands (46-49, 50-54 etc) in comparison with the proportion from the 2011 UK Census for the five screening areas of Greater 
Manchester [8]. This calculation assumed that all women in those age groups would have received both an invitation for mammography and to join the PROCAS study over the study recruitment period.

Age-standardised statistics were obtained by weighting the contribution of each woman to reflect the age distribution in the standard 2013 European population [13]. For risk factors, standardisation was undertaken by year, and by 5 year groups for incidence. Inference for standardised risk factors was based on a non-parametric bootstrap (10,000 resamples), and for standardised incidence a parametric bootstrap (Poisson); empirical 95\% confidence intervals were obtained [14, 15]. A linear model was used to predict mammographic density given age and BMI, to investigate if differences between the BMI distributions fully explained density difference between the groups. Age-standardised statistics were obtained for birth cohorts (born <1950, 1950-9 or $\geq 1960$ ). Tests for trend between the cohorts used the Cuzick (1985) test for continuous or ordered data, or a logistic regression chi-square test for binary risk factors.

\section{Results and discussion}

During the first phase of recruitment, the majority (70\%) of women were aged 50-64 years, with $23 \%$ aged 65-73 years and 7\% younger than 50 years. Most women were white British/Irish (91.0\%), 1.3\% were Asian, 4.0\% had other ethnicities and 3.7\% did not report ethnicity. In the second phase, a larger proportion of younger women were recruited: $43 \%$ were aged $46-49$ years and $49 \%$ aged $50-54$ years. The majority were again white British/Irish (89.0\%) but there were proportionally more Asian women (3.3\%) than in the first phase. Overall, almost the same proportion recruited in each phase stated a preference to be informed of their risk (94.5\% vs $95.0 \%)$.

In total 57,902 women were recruited to PROCAS; 906 of whom had previously developed breast cancer. A total of $891(1.54 \%)$ women self-identified on their questionnaires as being Asian or Asian British (12 with previous breast cancer), with 52,639 (90.9\%) who identified themselves as white British or Irish (830 with previous breast cancer). Proportional uptake of Asian women to PROCAS compared with the assumed Asian women population in Greater Manchester is shown in Table 1.

Overall entry to PROCAS amongst Asian women was lower than would be expected in the invited population as a whole. The relative uptake dropped from roughly 1 in 3 for Asian women in those aged 46-49 years to only 1 in 6 aged $\geq 65$ years.

After excluding those with previous breast cancer and not aged 46-73 years at entry, 879 Asian women and 51,779 white British/Irish women remained. Table 2 shows the age standardised risk factor summary at entry
Table 1 Proportion of Asian women in the local invited population compared with those entering PROCAS

\begin{tabular}{llll}
\hline $\begin{array}{l}\text { Age group } \\
\text { (year) }\end{array}$ & $\begin{array}{l}\text { Asian proportion at } \\
\text { screening ages in } \\
\text { Greater Manchester } \\
\text { population (census) }\end{array}$ & $\begin{array}{l}\text { Asian women } \\
\text { in PROCAS (\%) }\end{array}$ & $\begin{array}{l}\text { Relative proportion } \\
\text { entering PROCAS }\end{array}$ \\
\hline $46-49$ & $8.52 \%$ & $256(2.70 \%)$ & $32 \%$ \\
$50-54$ & $7.52 \%$ & $289(2.14 \%)$ & $28 \%$ \\
$55-59$ & $6.33 \%$ & $152(1.64 \%)$ & $26 \%$ \\
$60-64$ & $6.28 \%$ & $112(1.16 \%)$ & $19 \%$ \\
$65-69$ & $6.16 \%$ & $59(0.99 \%)$ & $16 \%$ \\
$70-74$ & $4.79 \%$ & $11(0.75 \%)$ & $16 \%$ \\
\hline
\end{tabular}

for women self-identified to be white British/Irish or Asian in the PROCAS study.

There were a number of differences in the incidence of risk factors that were reflected by a lower risk assessment for Asian women than white British/Irish women (mean 10 year risk $2.67 \%$ vs $3.07 \%$ ). A greater proportion of Asian women fell into the low-risk ( $<2 \% 10$-year risk) group (32.6\% vs $18.9 \%)$ and a lower proportion into the elevated risk ( $\geq 5 \% 10$ year) group (6.7\% vs $9.9 \%$ ).

Asian women had a later age at menarche than white British/Irish women and were more likely to be postmenopausal with an earlier age at menopause. On average, Asian women were less obese (mean BMI 26.5 vs $27.5 \mathrm{~kg} / \mathrm{m}^{2}$ ) and shorter (mean 1.57 vs $1.62 \mathrm{~m}$ ) than white British/Irish women. Asian women were less likely to be nulliparous $(9.7 \%$ vs $13.0 \%)$ and had larger families (26.7\% had four or more children compared with 10.0\%). In those with children, the age at first child was similar, as was the proportion with a first child aged $<17$ years. Asian women were less likely to have a family history of breast cancer $(10.4 \%$ vs $12.1 \%$ had one or more affected first-degree relatives), and much less likely to have ever used hormone therapy (20.3\% vs $38.3 \%$ ).

There were some differences in risk factors that are not included in the Tyrer-Cuzick risk assessment model. Alcohol use was substantially lower in Asian women than white British/Irish women (18.8\% vs $73.0 \%)$. Asian women gained an absolute $4 \%$ more weight since age 20 years than white British/Irish women, and they were less likely to exercise (49.9\% vs $72.2 \%)$. There was some evidence to suggest that mammographic density in Asian women was elevated compared to white British/Irish women, but the absolute difference was small after adjustment for age and BMI (1.8\% greater, $95 \%$ CI 0.04 to $3.3 \%)$.

Cohort trends in risk factors that are expected to increase breast cancer incidence were seen in both the Asian and white British/Irish populations (Table 3).

One of the largest changes was in the number of children and age at birth of first child. In the Asian group, there was a tendency for the older cohort to 
Table 2 Age standardised risk factor summary

\begin{tabular}{|c|c|c|c|c|}
\hline \multirow[t]{2}{*}{ Risk factor } & \multicolumn{2}{|c|}{ Mean (standard deviation) or Percentage (\%) } & \multirow{2}{*}{$\begin{array}{l}\text { Difference }(95 \% \mathrm{Cl}) \\
\text { (Asian - White) }\end{array}$} & \multirow[t]{2}{*}{$P$} \\
\hline & Asian & White & & \\
\hline \multicolumn{5}{|l|}{ Puberty } \\
\hline Age at menarche $(y)$ & $13.3(1.6)$ & $12.9(1.6)$ & 0.37 (0.2 to 0.5$)$ & $<0.001$ \\
\hline \multicolumn{5}{|l|}{ Height and weight } \\
\hline Body mass index $\left(\mathrm{kg} / \mathrm{m}^{2}\right)$ & $26.5(5.2)$ & $27.5(5.5)$ & $-0.97(-1.4$ to -0.6$)$ & $<0.001$ \\
\hline Weight (kg) & $65.5(13.4)$ & $71.6(14.8)$ & $-6.10(-7.1$ to -5.1$)$ & $<0.001$ \\
\hline Height (m) & $1.57(0.07)$ & $1.62(0.07)$ & $-0.045(-0.051$ to -0.039$)$ & $<0.001$ \\
\hline \multicolumn{5}{|l|}{ Reproductive factors } \\
\hline Nulliparous & $9.7 \%$ & $13.0 \%$ & $-3.39 \%(-5.5$ to $-1.0 \%)$ & 0.003 \\
\hline Age first child(y) & $24.7(5.2)$ & $24.4(5.1)$ & $0.36(-0.08$ to 0.8$)$ & 0.12 \\
\hline Children (n) & $2.7(1.7)$ & $2.0(1.2)$ & 0.65 (0.5 to 0.8$)$ & $<0.001$ \\
\hline Four or more $(y)$ & $26.7 \%$ & $10.0 \%$ & $16.73 \%$ (13.1 to $20.4 \%)$ & $<0.001$ \\
\hline 1 st $<17 y(y)$ & $1.6 \%$ & $1.6 \%$ & $0.00 \%(-0.9$ to $1.1 \%)$ & 0.9 \\
\hline \multicolumn{5}{|l|}{ Menopausal status } \\
\hline Pre-menopausal & $14.5 \%$ & $14.4 \%$ & $0.15 \%(-1.6$ to $1.9 \%)$ & 0.9 \\
\hline Peri-menopausal & $13.4 \%$ & $16.6 \%$ & $-3.17 \%(-5.2$ to $-1.1 \%)$ & 0.002 \\
\hline Post-menopausal & $72.0 \%$ & $69.0 \%$ & $3.01 \%$ (0.8 to $5.1 \%)$ & 0.007 \\
\hline Age menopause (post-menopausal) & $47.6(5.7)$ & $46.8(5.9)$ & 0.80 (0.3 to 1.3$)$ & 0.002 \\
\hline Hormone therapy (ever) & $20.3 \%$ & $38.3 \%$ & $-18.02 \%(-21.1$ to $-14.8 \%)$ & $<0.001$ \\
\hline \multicolumn{5}{|l|}{ Genetic disposition } \\
\hline 1 or more affected first-degree relatives & $10.4 \%$ & $12.1 \%$ & $-1.69 \%(-4.1$ to $0.8 \%)$ & 0.18 \\
\hline \multicolumn{5}{|l|}{ Mammographic density } \\
\hline Percent density (\%) & $30.2(18.1)$ & $27.7(17.3)$ & $2.52(1.1$ to 4.0$)$ & $<0.001$ \\
\hline Percent density (\%, BMI adjusted) & $28.6^{\mathrm{b}}$ & $26.8^{b}$ & 1.83 (0.04 to 3.3$)$ & 0.011 \\
\hline \multicolumn{5}{|l|}{ Overall 10-year risk (Tyrer-Cuzick model) } \\
\hline Mean (standard deviation) & $2.67(1.39)$ & $3.07(1.49)$ & $-0.405(-0.53$ to -0.26$)$ & $<0.001$ \\
\hline Percentage $\geq 5 \%$ & $6.7 \%$ & $9.9 \%$ & $-3.28 \%(-5.3$ to $-1.1 \%)$ & 0.003 \\
\hline Percentage $<2 \%$ & $32.6 \%$ & $18.9 \%$ & $13.73 \%(10.2$ to $17.3 \%)$ & $<0.001$ \\
\hline \multicolumn{5}{|l|}{ Other risk factors } \\
\hline Adult Weight gain (\% change weight since 20y) & $28.7(22.2)$ & $24.3(21.3)$ & 4.41 (3.4 to 6.0 ) & $<0.001$ \\
\hline Physical Activity (y/n) & $49.9 \%$ & $72.2 \%$ & $-22.29 \%(-26.7$ to $-18.0 \%)$ & $<0.001$ \\
\hline Physical activity(> 4 h/wk) & $58.0 \%$ & $62.7 \%$ & $-4.75 \%$ (-9.9 to $0.4 \%)$ & 0.067 \\
\hline Drink alcohol (any) & $18.6 \%$ & $73.0 \%$ & $-54.36 \%(-57.8$ to $-50.8 \%)$ & $<0.001$ \\
\hline
\end{tabular}

${ }^{a}$ Mean (standard deviation) is used for continuous data, and percentage (\%) for binary data

${ }^{\mathrm{b}}$ Predicted (age-standardised) density for a woman with BMI $26-28 \mathrm{~kg} / \mathrm{m}^{2}$

have given birth later and to have fewer children (31.1\% in cohort born before 1950 had four or more children compared with $22.1 \%$ born $\geq 1960$ ). There was also a doubling in nulliparity rates $(6.3 \%$ to 13.1\%). Similar trends were seen for white British/ Irish women. Changes in frequency of physical activity were also observed; younger Asian and white British/Irish women were less likely to exercise. Alcohol use was most prevalent for white British/Irish women born after 1950. Due to the large sample size, many of the trends of other risk factors in white
British/Irish women were statistically significant, but some differences were not large.

Rates of breast cancer by age group are presented in Table 4. Age standardised rates were lower in Asian women. Although this is in line with expectations from the analysis of risk factors, we lack statistical power to detect differences.

\section{Discussion}

The present study has found that the predicted breast cancer risk attributable to some reproductive and 
Table 3 Risk factor trends by birth cohort and ethnic group

\begin{tabular}{|c|c|c|c|c|c|c|c|c|}
\hline \multirow[b]{2}{*}{ Cohort: } & \multicolumn{4}{|l|}{ Asian } & \multicolumn{4}{|l|}{ White } \\
\hline & $<1950$ & $1950-9$ & $\geq 1960$ & $P_{\text {trend }}$ & $<1950$ & $1950-9$ & $\geq 1960$ & $P_{\text {trend }}$ \\
\hline Number & 157 & 375 & 347 & & $18222^{*}$ & 21,111 & 12,424 & \\
\hline Age range (y) & $60-73$ & $49-64$ & $46-55$ & & $60-73^{*}$ & $49-64$ & $46-55$ & \\
\hline Age at menarche $(y)^{a}$ & $13.2(1.6)$ & $13.3(1.7)$ & $13.2(1.6)$ & 0.6 & $12.9(1.6)$ & $13.0(1.5)$ & $13.0(1.7)$ & 0.002 \\
\hline Body mass index ${ }^{a}$ & $25.8(4.6)$ & $27.6(5.0)$ & $27.3(5.7)$ & 0.29 & $27.3(5.1)$ & $27.2(5.4)$ & $27.4(5.7)$ & $<0.001$ \\
\hline Weight $(\mathrm{kg})^{\mathrm{a}}$ & $63.0(11.5)$ & $69.4(14.1)$ & $66.7(13.9)$ & 0.8 & $70.6(13.6)$ & $71.0(14.7)$ & $72.7(15.5)$ & $<0.001$ \\
\hline Height $(m)^{a}$ & $1.56(0.06)$ & $1.59(0.06)$ & $1.56(0.07)$ & 0.047 & $1.61(0.06)$ & $1.61(0.06)$ & $1.63(0.07)$ & $<0.001$ \\
\hline Nulliparous ${ }^{\mathrm{b}}$ & $6.3 \%$ & $10.3 \%$ & $13.1 \%$ & 0.15 & $10.2 \%$ & $15.4 \%$ & $17.0 \%$ & $<0.001$ \\
\hline$\geq 4$ children $^{\mathrm{b}}$ & $31.5 \%$ & $25.9 \%$ & $22.1 \%$ & 0.004 & $12.3 \%$ & $7.5 \%$ & $8.1 \%$ & $<0.001$ \\
\hline Age at first child $(y)^{a}$ & $24.8(5.2)$ & $23.8(4.9)$ & $25.7(5.1)$ & 0.005 & $23.6(4.3)$ & $24.3(5.2)$ & $25.4(5.6)$ & $<0.001$ \\
\hline 1st child $<17 y^{b}$ & $1.1 \%$ & $2.3 \%$ & $2.0 \%$ & 0.18 & $0.8 \%$ & $2.5 \%$ & $2.3 \%$ & $<0.001$ \\
\hline Number children $(n)^{a}$ & $2.9(1.6)$ & $2.9(2.0)$ & $2.3(1.7)$ & $<0.001$ & $2.2(1.3)$ & $2.0(1.2)$ & $1.9(1.3)$ & $<0.001$ \\
\hline$\geq 1$ affected 1 st-degree relative $(\%)^{b}$ & $15.1 \%$ & $6.9 \%$ & $6.4 \%$ & 0.35 & $12.4 \%$ & $9.7 \%$ & $13.3 \%$ & 0.11 \\
\hline Adult weight gain $(\%)^{a}$ & $27.8(20.2)$ & $31.1(22.6)$ & $33.3(25.6)$ & 0.9 & $24.7(21.4)$ & $24.2(20.9)$ & $22.8(20.5)$ & $<0.001$ \\
\hline Physical activity $(\mathrm{y} / \mathrm{n})^{\mathrm{b}}$ & $52.0 \%$ & $51.5 \%$ & $39.9 \%$ & 0.35 & $75.2 \%$ & $73.8 \%$ & $62.3 \%$ & $<0.001$ \\
\hline Physical activity(> $17 \mathrm{~h} /$ month) ${ }^{\mathrm{b}}$ & $60.2 \%$ & $61.5 \%$ & $43.7 \%$ & 0.074 & $70.7 \%$ & $58.5 \%$ & $52.1 \%$ & $<0.001$ \\
\hline Drink alcohol $(y / n)^{b}$ & $20.4 \%$ & $16.3 \%$ & $14.2 \%$ & 0.6 & $68.1 \%$ & $77.9 \%$ & $75.1 \%$ & $<0.001$ \\
\hline
\end{tabular}

${ }^{*} n=41$ white British/Irish women aged 58-59 years excluded from the table because not represented in Asian cohort born before 1950

${ }^{a}$ Mean (standard deviation) presented

bercentage presented

hormonal risk factors is lower in Asian women than in the white British/Irish population attending mammographic screening in Greater Manchester. Asian women were more likely to be protected by multiple child births, absence of alcohol or hormone therapy use and a slightly later age at menarche. However, they were more likely to have increased risks related to larger adult weight gains and lower levels of physical activity.

The most thorough examination of ethnicity and breast cancer risk in the UK to date was analysis based on the Million Women Study (MWS). This recruited women, on average, 13 years earlier than in the PROCAS study [16]. It found that South Asian women had a reduced breast cancer incidence compared with white women (relative risk 0.82 , 95\% CI $0.72-0.94$ ). By way of comparison, in this study the average 10 year standardised predicted relative risk for Asian vs white women was $2.67 / 3.07=0.87$.

PROCAS is a more recent birth cohort than in the MWS, in which the youngest women were born in 1951 . Thus the PROCAS and MWS cohorts represent different generations of Asian women. Furthermore, it is possible that the majority of Asian women in the MWS were born and brought up in Asia, as mass migration to the UK only began after 1947. We do not have data on place of birth in PROCAS, but it is probable that most Asian women in PROCAS were born or resided in the UK during pubertal development. Approximately 5.3\%

Table 4 Rates of breast cancer by age and ethnic group

\begin{tabular}{|c|c|c|c|c|c|c|c|c|c|}
\hline & White & & & & Asian & & & & \\
\hline Age $(y)$ & $\begin{array}{l}\text { Women } \\
\text { N (\%) }\end{array}$ & $\begin{array}{l}\text { Breast Cancer } \\
\mathrm{N}(\%)\end{array}$ & $\begin{array}{l}\text { Follow up } \\
(y)\end{array}$ & $\begin{array}{l}\text { Annual rate } \\
\text { (per 1000) }\end{array}$ & $\begin{array}{l}\text { Women } \\
\text { N (\%) }\end{array}$ & $\begin{array}{l}\text { Breast Cancer } \\
\mathrm{N}(\%)\end{array}$ & $\begin{array}{l}\text { Follow up } \\
\text { (y) }\end{array}$ & $\begin{array}{l}\text { Annual rate } \\
\text { (per 1000) }\end{array}$ & Weights \\
\hline $46-49$ & $256(29 \%)$ & $2(13 \%)$ & 1042.4 & 1.9 & $10,380(20 \%)$ & $164(15 \%)$ & $39,679.8$ & 4.1 & 22 \\
\hline $50-54$ & 289 (33\%) & $9(60 \%)$ & 1423.8 & 6.3 & $13,526(26 \%)$ & $246(23 \%)$ & $61,907.0$ & 4.0 & 22 \\
\hline $55-59$ & $152(17 \%)$ & $2(13 \%)$ & 802.1 & 2.5 & 9735 (19\%) & 184 (17\%) & $48,530.3$ & 3.8 & 20 \\
\hline $60-64$ & $112(13 \%)$ & $1(7 \%)$ & 579.8 & 1.7 & 9870 (19\%) & 277 (26\%) & $48,984.0$ & 5.7 & 19 \\
\hline $65-69$ & $59(7 \%)$ & $1(7 \%)$ & 310.3 & 3.2 & $6700(13 \%)$ & 174 (16\%) & $33,371.6$ & 5.2 & 17 \\
\hline $70-73$ & $11(1 \%)$ & $0(0 \%)$ & 54.1 & 0 & $1588(3 \%)$ & $31(3 \%)$ & 7819.4 & 4.0 & 0 \\
\hline Age-star & dized (95\% Cl) & & & $3.2(1.6-5.2)$ & & & & $4.5(4.2-4.8)$ & \\
\hline
\end{tabular}

a Follow up is the total number of women-years in each group from questionnaire to last follow up

${ }^{b}$ European standard population (2013) weights. Standardised rates only include women aged 46-69 years due to small number in Asian 70-73 years group 
of the Asian group in the MWS reported a first-degree relative with breast cancer, compared with $9.5 \%$ of the white group. In the present study, the age-standardised percentage was $10.4 \%$ of Asian women compared with $12.1 \%$ of the white British/Irish population. The much closer percentages between ethnic groups in our study might reflect that previous generations in Asia had much lower breast cancer incidences and shorter lifespans. We found a small increase in mammographic density in Asian women compared to white British/Irish women after adjustment for age and BMI, which is in line with previous studies [17].

Some important trends in risk factors for Asian and white British/Irish women were observed, for instance, later ages at first birth were observed within the more recent birth cohorts. Previous research has indicated that part of the change in incidence in Asian populations who migrate to Western countries might be due to changes in parity [16]. The trend in the Asian group here was quite clear, with a doubling of nulliparity rates, fewer children and a later age at first birth. In addition, adult weight gain is becoming an established predictor of post-menopausal breast cancer risk [18]. Asian women had proportionally greater adult weight gains than white British/Irish women and they were also far less likely to undertake regular physical activity or meet physical activity guidelines, particularly in the more recent birth cohort. This pattern is also expected to lead to increasing breast cancer risk for Asian women, including those women who are currently pre-menopausal.

The current study has several limitations. There was some missing data in the questionnaire (see Additional file 1), and we only used fully complete fields. Methods to assess physical activity and weight change were rather crude, and more refined follow-up studies could be planned. Recruitment to PROCAS depended on women attending breast screening and volunteering to join the study. Women who do not attend screening may have different risk factor profiles than those who do. For example, attendance is linked with socio-economic status which in turn is also linked with increased rates of overweight and obesity. Uptake to PROCAS was higher in more affluent areas. However, the issue of non-attendance affects both ethnic groups examined here, so the analysis is best interpreted as risk factors in women who attend screening. Further, uptake was similar to that in the MWS. But overall, an important limitation is it is possible that Asian women who joined PROCAS are not representative of the Asian population in Greater Manchester. Asian women only represented $1.5 \%$ of the total PROCAS population and the numbers of breast cancers in this group were small. Nonetheless, they probably represent a population of younger Asian women who attend screening and have been born or brought up in the UK. It is possible that differences in risk factor distributions are not very generalizable beyond the study, and that differences may also arise due to a relatively small sample of Asian women. However, many of the differences are large and consistent with prior expectations (e.g. Asian women were shorter, less obese and less likely to drink alcohol), and some of the differences are quite large, so there is some qualitative support that the differences may well be generalizable.

Breast cancer is largely attributable to non-genetic factors. For example, studies have shown that women born in areas with low rates of the disease have low rates of the disease when they migrate to a country with higher rates, but that the risk in subsequent generations increases towards the rate of women born in the country [5]. We observed a lower predicted risk of breast cancer in women with an Asian heritage in this study. Unfortunately the study lacked statistical power to test whether this risk assessment is accurate. Additional follow-up of the PROCAS cohort and further studies are warranted to help assess these aspects.

\section{Conclusion}

In conclusion, the current study suggests that Asian women remain at lower risk of breast cancer than white British/Irish women. However, trends in risk factors in both populations suggest an ongoing increase in breast cancer risks. For Asian women, preventive interventions might focus on reducing risks from modifiable risk factors such as weight reduction and increasing levels of physical activity.

\section{Additional file}

Additional file 1: PROCAS questionnaire. (DOCX $17 \mathrm{~kb})$

\section{Abbreviations}

BMI: Body mass index; GMBSP: Greater Manchester Breast Screening Programme; MWS: Million women study; NHS: National Health Service; NHSBSP: National Health Service Breast Screening Programme; NIHR: National Institute for Health Research; PROCAS: Predicting Risk of Cancer at Screening; UK: United Kingdom; VAS: Visual analogue scale

\section{Acknowledgements}

The authors thank other members of the PROCAS group, including study radiologists (Prof Caroline Boggis, Dr. Megan Bydder, Dr. Emma Hurley and Dr. Rumana Rahim) and advanced radiography practitioners (Amanda Bath, Rita Borgen, Miriam Griffiths, Jill Johnson and Elizabeth Lord) for mammography reporting. This work was supported by the National Institute for Health Research (NIHR) and Genesis Breast Cancer Prevention Appeal (references GA10-033 and GA13-006).

\section{Funding}

This article presents independent research funded by the National Institute for Health Research (NIHR) under its Programme Grants for Applied Research programme (Reference Number RP-PG-0707-10031). The views expressed are those of the author(s) and not necessarily those of the NHS, the NIHR or the Department of Health. 


\section{Availability of data and materials}

The datasets generated and/or analysed during the current study are not publicly available as they contain information that could compromise research participant privacy/consent, but are available from the corresponding author on reasonable request.

\section{Authors' contributions}

Conception: DGE, AB. Data collection: SS, PS, FI. Data analysis: DGE, AB, EH. Manuscript writing: DGE, AB, MH, SA, EH, PS, LD, SS, DW, JC, MW, AJ, FH, AM, $A H, F I$. Approval of final version: DGE, AB, MH, SA, EH, PS, LD, SS, DW, JC, $\mathrm{MW}, \mathrm{AJ}, \mathrm{FH}, \mathrm{AM}, \mathrm{AH}, \mathrm{FI}$. All authors read and approved the final manuscript.

\section{Ethics approval and consent to participate}

This study was approved by the North West 7 Research Ethics Committee - GM Central (study REC reference 09/H1008/81).

Informed consent had been obtained from all of the participants confirming their agreement to participate in the study.

\section{Consent for publication}

Not applicable

\section{Competing interests}

The authors declare that they have no competing interests.

\section{Publisher's Note}

Springer Nature remains neutral with regard to jurisdictional claims in published maps and institutional affiliations.

\section{Author details}

Department of Genomic Medicine, Division of Evolution and Genomic Science, MAHSC, University of Manchester, Central Manchester NHS Foundation Trust, Oxford Road, Manchester, UK. Division of Informatics, Imaging and Data Sciences, Faculty of Biology, Medicine and Health, University of Manchester, Manchester Academic Health Science Centre, Oxford Road, Manchester, UK. ${ }^{3}$ Nightingale \& Prevention Breast Cancer Centre, University Hospital of South Manchester, Manchester, UK. ${ }^{4}$ Centre for Cancer Prevention, Wolfson Institute of Preventive Medicine, Queen Mary University of London, London, UK. ${ }^{5}$ School of Medical Sciences, University of Manchester, Oxford Road, Manchester, UK. ${ }^{6}$ The Christie, Manchester, UK. ${ }^{7}$ Department of Genomic Medicine, MAHSC, St Mary's Hospital, Central Manchester NHS Foundation Trust, Manchester M13 9WL, UK

\section{Received: 18 April 2017 Accepted: 17 January 2018}

\section{Published online: 25 January 2018}

\section{References}

1. Jack RH, Møller $H$, Robson T, Davies EA. Breast cancer screening uptake among women from different ethnic groups in London: a population-based cohort study. BMJ Open. 2014:4:e005586.

2. Bansal N, Bhopal RS, Steiner MF, Brewster DH. Scottish health and ethnicity linkage study. Major ethnic group differences in breast cancer screening uptake in Scotland are not extinguished by adjustment for indices of geographical residence, area deprivation, long-term illness and education. Br J Cancer. 2012;106:1361-6.

3. Sokal R. A critical review of the literature on the uptake of cervical and breast screening in British south Asian women. Qual Prim Care. 2010;18:251-61.

4. Torre LA, Bray F, Siegel RL, Ferlay J, Lortet-Tieulent J, Jemal A. Global cancer statistics, 2012. CA Cancer J Clin. 2015:65:87-108.

5. Ziegler RG, Hoover RN, Pike MC, et al. Migration patterns and breast cancer risk in Asian-American women. J Natl Cancer Inst. 1993;85:1819-27.

6. Collaborative Group on Hormonal Factors in Breast Cancer. Familial breast cancer: collaborative reanalysis of individual data from 52 epidemiological studies including 58,209 women with breast cancer and 101,986 women without the disease. Lancet. 2001;358:1389-99.

7. Health \& Social Care Information Centre. Breast screening Programme England 2011-2012. 2013. http://www.hscic.gov.uk/catalogue/PUB10339. Accessed 1 Aug 2016

8. Office for National Statistics. 2011 census analysis for Manchester. 2012. http://www.manchester.gov.uk/info/200088/statistics_and_census/438/. Accessed 15 Feb 2017.
9. Evans DG, Astley S, Stavrinos P, Harkness E, Donnelly LS, Dawe S, Jacob I, Harvie M, Cuzick J, Brentnall A, Wilson M, Harrison F, Payne K, Howell A. Improvement in risk prediction, early detection and prevention of breast cancer in the NHS breast screening Programme and family history clinics: a dual cohort study. Southampton: NIHR Journals Library; 2016.

10. Tyrer J, Duffy SW, Cuzick J. A breast cancer prediction model incorporating familial and personal risk factors. Stat Med. 2004;23:1111-30.

11. Wu Y, Zhang D, Kang S. Physical activity and risk of breast cancer: a metaanalysis of prospective studies. Breast Cancer Res Treat. 2013;137:869-82.

12. Brentnall AR, Harkness E, Astley S, Donnelly L, Stavrinos P, Sampson S, Fox L, Sergeant J, Harvie M, Wilson M, Beetles U, Gadde S, Lim Y, Jain A, Bundred S, Barr N, Reece V, Howell A, Cuzick J, Evans DG. Mammographic density adds accuracy to both the Tyrer-Cuzick and Gail breast cancer risk models in a prospective UK screening cohort. Breast Cancer Res. 2015;17:147.

13. Eurostat. Revision of the European standard population. Luxembourg: Publications Office of the European Union; 2013. https://doi.org/10.2785/11470.

14. Davison AC, Hinkley DV. Bootstrap methods and their application. Cambridge: Cambridge University Press; 1997.

15. Cuzick J. A Wilcoxon-type test for trend. Stat Med. 1985;4:87-90.

16. Gathani T, Ali R, Balkwill A, Green J, Reeves G, Beral V, Moser KA, Million Women Study Collaborators. Ethnic differences in breast cancer incidence in England are due to differences in known risk factors for the disease: prospective study. Br J Cancer. 2014;110:224-9.

17. McCormack VA, Perry N, Vinnicombe SJ, Silva dos Santos I. Ethnic variations in mammographic density: a British multiethnic longitudinal study. Am J Epidemiol. 2008;168:412-21.

18. Keum A, Greenwood DC, Lee DH, Kim R, Aune D, Ju W, Hu FB, Giovannucci EL. Adult weight gain and adiposity-related cancers: a dose-response metaanalysis of prospective observational studies. J Natl Cancer Inst. 2015;107 https://doi.org/10.1093/jnci/dju428.

\section{Submit your next manuscript to BioMed Central and we will help you at every step:}

- We accept pre-submission inquiries

- Our selector tool helps you to find the most relevant journal

- We provide round the clock customer support

- Convenient online submission

- Thorough peer review

- Inclusion in PubMed and all major indexing services

- Maximum visibility for your research

Submit your manuscript at www.biomedcentral.com/submit
Biomed Central 